\title{
Neurotoxic Hippocampal Lesions Have No Effect on Odor Span and Little Effect on Odor Recognition Memory But Produce Significant Impairments on Spatial Span, Recognition, and Alternation
}

\author{
Paul A. Dudchenko, ${ }^{1}$ Emma R. Wood, ${ }^{2}$ and Howard Eichenbaum ${ }^{3}$ \\ ${ }^{1}$ Department of Psychology, University of Stirling, Stirling, FK9 4LA Scotland, ${ }^{2}$ Department of Neuroscience, University of

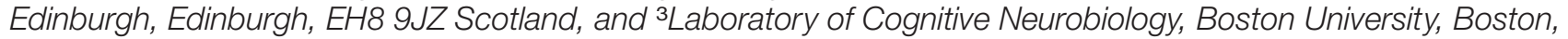 \\ Massachusetts 02215
}

\begin{abstract}
Recent work has shown that lesions of the hippocampus in monkeys cause deficits in the capacity to remember increasing numbers of objects, colors, and spatial locations (Beason-Held et al., 1999). However, others have observed that hippocampectomized monkeys can show intact memory for a list of objects or locations (Murray and Mishkin, 1998). We wished to explore the effects of hippocampal damage on the capacity of memory in the rodent and, to do so, developed novel "span" tasks in which a variable number of odors or locations had to be remembered. In the odor span task (experiment 1), rats were trained on a nonmatching to sample task in which increasing numbers of odors had to be remembered. Half of the trained rats received ibotenic acid lesions of the hippocampus. Postoperatively, hippocampectomized animals did not differ from control animals even when required to remember up to 24 odors. However, when tested on delayed retention of a list of 12
\end{abstract}

odors, rats with hippocampal lesions were impaired at a long delay. Also, these rats were impaired on a subsequent test of delayed spatial alternation. In a spatial span task (experiment 2), naive rats were trained on a nonmatching to sample task in which a variable number of locations had to be remembered. After this, half of the animals received ibotenic acid lesions. Postoperatively, hippocampectomized animals performed above chance levels when required to remember a single cup location, but were unable to remember more. Subsequent testing on another spatial delayed alternation task suggested that hippocampectomized rats could recognize, but could not inhibit their approach to previously visited locations.

Key words: hippocampus; ibotenic acid; delayed nonmatching to sample; span; olfactory memory; spatial memory; delayed alternation; T-maze
The hippocampus has been implicated in memory since the initial observations of severe anterograde amnesia after medial temporal lobe resection in humans (Scoville and Milner, 1957; Corkin, 1984). However, studies involving more selective damage to the hippocampus or fornix in nonhuman primates (Alvarez et al., 1995; Murray and Mishkin 1998) and rodents (Aggleton et al., 1986; Rothblat and Kromer, 1991; Mumby et al., 1992; Otto and Eichenbaum, 1992; Kesner et al., 1993; Shaw and Aggleton, 1993) have called into question the notion that the hippocampus itself is critical for memory of individual items. These observations, together with evidence that lesions of the parahippocampal region produce impairments on the same tasks (Zola-Morgan et al., 1989; Otto and Eichenbaum, 1992; Meunier et al., 1993; Suzuki et al., 1993; Mumby and Pinel, 1994; Ennaceur et al., 1996; Aggleton et al., 1997) have led some to propose that the parahippocampal region, and not the hippocampus, is required for recognition memory (Eichenbaum et al., 1994; Murray, 1996).

In one of the more striking demonstrations of intact memory after hippocampal damage, Murray and Mishkin (1998) trained monkeys on a delayed nonmatching to sample task that required

\footnotetext{
Received Oct. 18, 1999; revised Jan. 4, 2000; accepted Feb. 1, 2000.

This work was supported by National Institutes of Health Grant MH52090. We thank Kara Agster, Lauren Costa, Geanbry Demming, John Faherty, and Melissa Shuster for their assistance with animal testing and histology.

P.D. and E.W. contributed equally to the experiments described in this paper.

Correspondence should be addressed to Paul Dudchenko, University of Stirling, Department of Psychology, Stirling, FK9 4LA, Scotland. E-mail: p.a.dudchenko@ stir.ac.uk.

Copyright (C) 2000 Society for Neuroscience $\quad 0270-6474 / 00 / 22964-14 \$ 15.00 / 0$
}

memory for lists of three, five, or 10 sample objects. They observed no difference in the performance of control monkeys and monkeys with selective lesions of the hippocampus and amygdala with increasing list length. Even when tested with a list of 40 sample objects, monkeys with hippocampal damage performed as well as normal subjects. These animals were also unimpaired when required to remember two locations over a $20 \mathrm{sec}$ delay. These data are consistent with studies in the rat (Mumby et al., 1992) and suggest that the hippocampus is not necessary for object or location recognition memory.

These observations are at odds with data recently reported by Beason-Held et al. (1999), who examined memory for multiple items in monkeys with ibotenic acid lesions of the hippocampus. In their study, hippocampectomized monkeys were tested on a "memory span" task in which the number of stimuli to-beremembered (the span) was increased after every correct response. Monkeys were tested on spatial location, color, and object span tasks, and hippocampectomized monkeys remembered fewer numbers of each of these items. Beason-Held et al. (1999) concluded that damage to the hippocampus alone is sufficient to produce impairments in tasks in which memory load is high.

In rats, to our knowledge, only two studies have examined nonspatial list learning (Steele and Rawlins, 1989, 1993). In the second of these studies, rats with hippocampal aspiration lesions were slightly impaired in remembering lists of distinctive goal boxes presented in a Y-maze apparatus. However, because this impairment was similar at all list lengths, it did not depend on the memory load per se. 

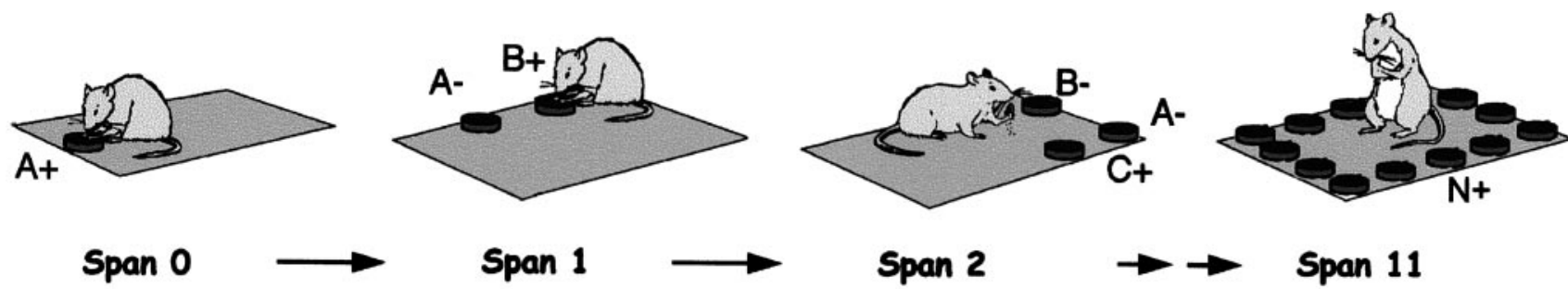

Span 2

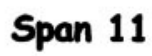

Figure 1. Schematic of the odor span task. Animals are first presented with a cup of sand scented with a specific odor (e.g., $A$ ). After digging in the sand and retrieving a buried reward, the animal is removed from the platform, and a second cup of sand, scented with a different odor $(B)$ is added. The animal's task on being returned to the platform is to remember odor $A(-)$ and dig at the different odor $B(+)$. Additional cups of sand, scented with different odors, are presented in the same manner.

In the current study, we sought to explore the contribution of the hippocampus to normal memory capacity in rodents using novel odor and location span tasks. These assessed recognition memory for increasing numbers of previously presented items. In humans, the capacity for recognizing familiar items represented in any order is practically limitless for visual stimuli (Standing, 1973) and is thus distinct from the traditional limit (span) for the number of items recalled in the same order as presented (Miller, 1956).

The current findings have been presented previously in abstract form (Dudchenko et al., 1998).

\section{EXPERIMENT 1: ODOR SPAN TASK}

\section{Materials and methods}

Subjects. The subjects were 16 male Long-Evans rats, weighing between 175 and $225 \mathrm{gm}$ at the beginning of training. Rats were moderately food-deprived and were permitted ad libitum access to water during training and testing. Rats were kept on a $12 \mathrm{hr}$ light/dark cycle and tested during the light phase of the cycle.

Apparatus and materials. Training and testing (except where noted) took place on a $3 \times 3$ foot square black Plexiglas platform with a 1.25-inch-tall border, placed on a pair of wooden blocks so that it rested $\sim 39$ inches above the floor. Odors were mixed in sand (see below) and presented in clear Nalgene cups $(25 / 8$-inch-diameter) placed on the platform. To keep the animals from tipping the cups over, they were affixed to the platform via strips of Velcro on the bottom of the cups. The complementary pieces of Velcro on the platform were spaced equally along its perimeter, such that a cup could be attached to any of 24 positions along the platform edges. Thus, cups could be placed in any of the four corners of the platform or in any of five positions along each side of the platform.

Shaping. Rats were habituated to handling for $3 \mathrm{~d} \mathrm{(3-5} \mathrm{min} / \mathrm{d})$ before training. In training, rats were initially shaped to dig in a cup of unscented playground sand (100 gm) for buried Froot Loop (Kellogg's) cereal rewards. Once the animals reliably dug in the sand for a single reward regardless of the location of the cup on the platform, they were introduced to scented cups of sand.

Odors. To scent the sand, $0.5 \mathrm{gm}$ of an individual household spice was mixed with the $100 \mathrm{gm}$ of sand. Twenty-five different scents were used in the current experiment: cocoa, cumin, orange, lemon, celery, thyme, basil, fennel, paprika, parsley, allspice, coffee, dill, cloves (0.1 gm), marjoram, mint, cinnamon, oregano, tea, ginger, garlic, caraway, anise, sage, and nutmeg.

Odor nonmatching to sample. Once the animals dug readily in the scented cups, they were trained on a nonmatching to sample (NMS) contingency. In the sample phase of each trial, the animal was presented with a cup of sand scented with a particular odor. After the animal dug in the scented sand and retrieved the cereal reward, it was removed from the platform and placed in an opaque bucket. The experimenter then moved this cup to a new location on the opposite side of the platform and added a second cup, scented with a different odor, to the platform. For the choice phase of the trial, the animal was removed from the bucket and placed on the platform opposite the two cups. The animal's task was to approach the cups, sniff the sand, and select the cup containing the new scent. Reinforcement was available only in this cup. A choice was scored if the rat dug or placed its paws on the sand. Animals were given 10-12 NMS trials each day until they reliably selected the new odor. The odors used each day were taken randomly from a pool of 25 different scents, and over the course of training all animals were exposed to all odors regularly.

Odor span task. After acquisition of the nonmatching to sample contingency, animals were introduced to the odor span task (Fig. 1). Trials in this task began with a sample and choice phase, identical to the NMS trials described above. The difference between the span task and the NMS trials was that, after a correct choice, the animal was returned to the opaque bucket, and an additional scented cup was placed onto the platform in a random position. The previously presented cups were also moved to different locations, and thus the spatial location of the cups on the platform bore no relation to which cup was rewarded. The animal was returned to the platform, and its task was to remember which two odors it had already selected (i.e., the initial sample odor and the second odor) and to choose the third odor. Only the cup with the new odor was baited, and if the animal correctly selected this cup without selecting the previously sampled cups, it was permitted to consume the cereal reward and then returned to the bucket. One new odor was added each time the animal made a correct choice. The trial ended when the animal dug in an odor cup it had previously sampled. The number of cups that the animal was successfully able to remember before making its first mistake was taken to be the span for that trial. Because there is no memory requirement when the first cup is presented, the span is equal to the number of cups presented and chosen sequentially without error minus 1. After making an incorrect response, the animal was returned to the bucket, and a new span trial, beginning again with a single sample, was started. In this phase of training, animals were given as many trials as possible within a 15-20 min testing period (typically between two and five trials) each day.

Twelve-odor span task. Once the average span of a given animal appeared to be stable ( 2 consecutive days with mean spans $\geq 5$ or at least 20 sessions of training), it was moved into the final presurgery phase of testing. In this phase, animals received one trial per day in which they were presented with additional odors, successively added in the manner described above, until 12 odors had been presented. The initial incorrect response was again used to calculate the animal's span. However, after a mistake, the animal was permitted to continue sampling the different scented cups on the platform until it selected the correct cup. After selecting the correct cup, the animal continued with increasing span lengths until all 12 odors had been sampled. Thus, in addition to the measure of span, it was possible to record whether or not the animal made a correct choice at each of the 11 spans tested. Training in this phase of the task lasted for $7 \mathrm{~d}$.

Probe sessions. To verify that the animals were using the scent of the sand to solve the task, two probe sessions were conducted. The first probe, termed "no reward", was designed to test whether the scent of the buried cereal reward itself controlled behavior. In this session, the animal was presented with increasing numbers of scented cups in the same way as the normal daily session. No cereal reward, however, was available in the correct cups. A reward was dropped into the cup only after the animal made its choice response by digging in the correct cup.

The second probe, termed "cup change", was designed to test whether the animals were marking the cups or the sand when they sampled them. At two points during the successive addition of odor cups, span length $=$ 4 (five cups on the platform) and span length $=8$ (nine cups on the platform), all of the cups and sand were replaced with new cups and new sand (containing the same odors). If the animals' performance of the task 
relied on marking the cups or sand, replacing the cups should significantly disrupt performance at the span length of 4 and 8 .

Hippocampal lesions. After $7 \mathrm{~d}$ with the 12-odor span test and the two probe sessions, performance-matched animals were assigned to either the "control" or "hippocampal" conditions. In the surgery control group, animals were preanesthetized with Halothane, then fully anesthetized with Nembutal and placed in a stereotaxic instrument (Kopf, Tujunga, CA). The dura above the hippocampus was exposed and penetrated with a needle, and the wound was then sutured. Two animals in the control group did not reach a satisfactory level of anesthesia for surgery and thus served as unoperated controls.

The hippocampal animals were anesthetized in the same manner, and after exposure of the dura, 14 injections of ibotenic acid were made in each hemisphere using the technique of Jarrard (1989). Specifically, injections of ibotenic acid $(10 \mu \mathrm{g} / \mu \mathrm{l})$ were infused at anteroposterior (AP) -2.4 (from bregma), mediolateral (ML) \pm 1.0 , dorsoventral (DV) $-3.2(0.2 \mu \mathrm{l})$; $\mathrm{AP}-3.0, \mathrm{ML} \pm 1.4, \mathrm{DV}-3.4,-2.9(0.1 \mu \mathrm{l}) ; \mathrm{ML} \pm 3.0, \mathrm{DV}$ $-3.0(0.2 \mu \mathrm{l}) ; \mathrm{AP}-4.0, \mathrm{ML} \pm 2.1, \mathrm{DV}-3.3,-2.3(0.1 \mu \mathrm{l}) ; \mathrm{ML} \pm 3.7, \mathrm{DV}$ $-3.0(0.2 \mu \mathrm{l})$; $\mathrm{AP}-4.8, \mathrm{ML} \pm 5.1, \mathrm{DV}-8.0(0.2 \mu \mathrm{l})$; ML $\pm 4.1, \mathrm{DV}-7.2$ $(0.2 \mu \mathrm{l}),-3.5(0.1 \mu \mathrm{l}) ; \mathrm{AP}-5.7, \mathrm{ML} \pm 4.5,5.1, \mathrm{DV}-3.6(0.2 \mu \mathrm{l}) ; \mathrm{ML}$ $\pm 5.1, \mathrm{DV}-7.4,-5.5,-4.5(0.1 \mu \mathrm{l})$.

All animals were permitted ad libitum food access after surgery and allowed 2 weeks of recovery before being food-deprived and returned to behavioral testing.

Postoperative testing. All animals were retrained on the NMS rule until they performed at $\geq 80 \%$ correct, in a session of at least seven trials, for $2 \mathrm{~d}$. On reaching this criterion, animals were tested for $7 \mathrm{~d}$ on the 12-odor span task.

Probe sessions. To test the possibility that animals may have used the scent of the reward or marked the cups or sand after surgery, the no reward and the cup change probes were repeated. In addition, to test whether the animals were performing at a ceiling level, two 25-ODOR SPAN probe trials were run. These trials were identical to the normal 12-odor span task initially but continued with the spans until 25 different odors were presented. As in the no reward and cup change probes, reward was provided only after the animal made its choice.

Odor delayed nonmatching to sample. After the span testing and probe sessions, animals were tested on a variable delay NMS task. This task proceeded in the following manner. In the sample phase, the animal was presented with 12 differently scented, baited cups, one at a time. The presented scents were the same as those used in the previous training and thus were presumably familiar to the animals. The animal was then removed from the testing room for a delay of $15,30,60$, or $180 \mathrm{~min}$. On its return to the testing room, the animal was presented with a choice between each sample and an odor it had not sampled on that day. During the choice phase, the previously sampled odor was represented in a different cup containing different but identically scented sand. The animal was rewarded for digging in the cup containing the odor that had not been presented during the sample phase of the trial, and the reward was dropped into the correct cup only after the animal made its choice. Each delay was tested for every animal, and the sequence of testing across delays was the same for all animals: day 1,15 min; day 2, $60 \mathrm{~min}$; day 3, $180 \mathrm{~min}$; day 4, $30 \mathrm{~min}$.

Alternation on a T-maze. After completion of the delay testing, animals were tested in a spatial delayed alternation task on a T-maze. The T-maze was constructed from Plexiglas and consisted of a 12-cm-wide black floor and transparent walls $16.5-\mathrm{cm}$-high, a 70-cm-long stem, and a $152 \mathrm{~cm}$ cross piece that formed the choice arms. Rewards were placed in opaque Nalgene cups attached with Velcro at the end of each arm. Training took place in a room separate from that used for odor testing, with a window in one wall and a variety of salient distal objects on the remaining walls. The procedure was the same as that described by Neave et al. (1994). In the sample phase of the task, the animal was placed at the beginning of the stem and allowed to traverse one arm of the $\mathrm{T}$ to obtain a cereal reward. During the sample phase one arm of the T was blocked with a Plexiglas door, and thus the sample was a "forced sample." After consumption of the reward, the animal was returned to the beginning of the stem, which was blocked off with an opaque Plexiglas door, and waited for a $15 \mathrm{sec}$ delay. After the delay, the Plexiglas door was removed, and the animal was permitted to select either arm of the T. An arm choice was defined as entry into an arm of the $\mathrm{T}$ to the extent that all four paws rested within the arm. Only the arm that had not been selected in the sample phase contained reward. If the animal entered the incorrect arm, it was blocked off in that arm for $10 \mathrm{sec}$. Animals were run in squads of four, and the intertrial interval was thus the time required to run the

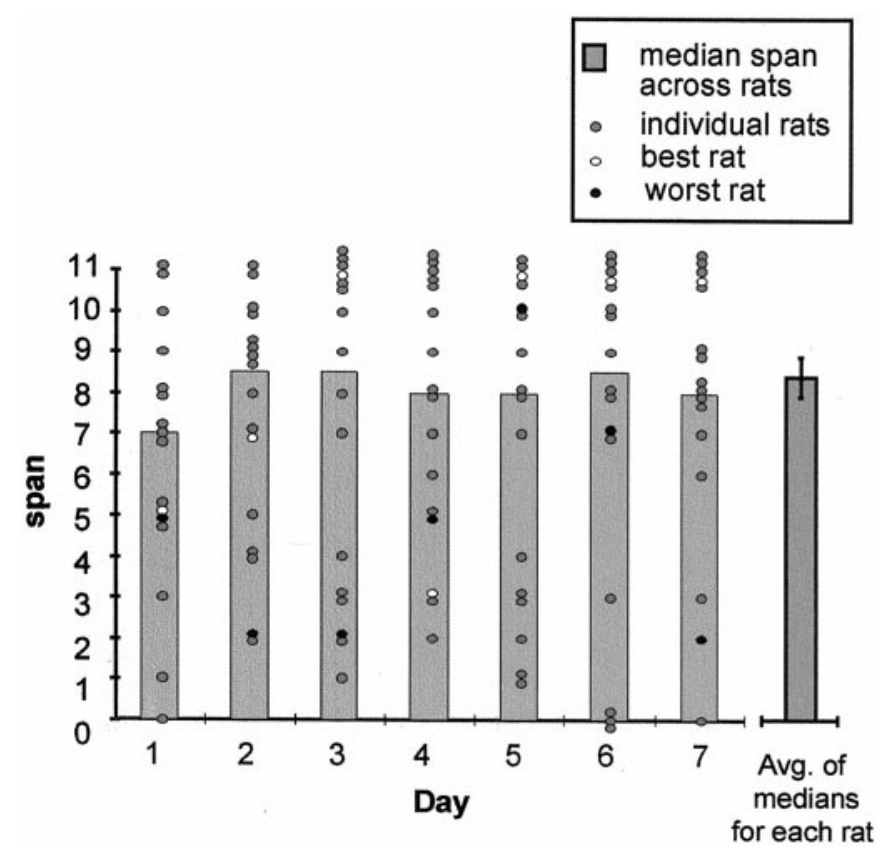

Figure 2. Median odor spans across $7 \mathrm{~d}$ of training. The average of medians for each rat was $8.38 \pm 0.49$, although individual spans (shown as dots) varied markedly in their spans across days. White dots indicate the daily spans for the animal with the highest median span across the entire $7 \mathrm{~d}$ period; black dots indicate the animal with the lowest median across the $7 \mathrm{~d}$ period.

remaining three animals $(\sim 5 \mathrm{~min})$. Animals were given six trials daily (three left and three right forced samples, in random order) for $12 \mathrm{~d}$. After this, the animals were tested for an additional $9 \mathrm{~d}$ in which the animal was "free" to choose either arm of the T-maze during the sample phase, with the opposite arm again being correct during the choice phase.

Histology. After completion of testing, animals were given an overdose of Nembutal and transcardially perfused with saline, followed by a $10 \%$ formalin solution. Brains were removed, and hippocampectomized brains were fixed in a gelatin/glutaraldehyde solution. Brains were sectioned at $50 \mu \mathrm{m}$ and stained with cresyl violet.

Statistical analysis. Statistical analysis was performed on SPSS for Windows, release 8.0.1. Comparisons of group performance relative to chance levels of performance were done using one-sample $t$ tests.

\section{Results}

\section{Acquisition and performance of the odor span task}

Animals were trained in the two-choice, nonmatching to sample task for an average of $6.35 \mathrm{~d}$ (range, 2-17) until they reliably selected the nonmatching odor. Animals were then given a minimum of eight sessions in the basic span task and on average required 12.1 sessions (range, 8-20) to reach a stable level of performance ( $2 \mathrm{~d}$ with spans $\geq 5$ or a maximum of $20 \mathrm{~d}$ training).

Animals were next placed in the 12-odor span task, in which a single daily trial was given with successive spans up to 11 (12 odors) total. Figure 2 illustrates the median performance of the animals on each of the seven sessions of the 12-odor span. The average of each animal's median span across these $7 \mathrm{~d}$ was 8.38 $(\mathrm{SE} \pm 0.49)$. However, the spans of each animal varied across days. For example, if one considers the performance of the best (Fig. 2, white circles; highest overall median across 7 d) and worst (Fig. 2, black circles; lowest overall median) animal on each of the 7 test days, it is evident that individual animals varied in their spans across sessions.

Figure 3 presents the accuracy of performance at each span level, across the $7 \mathrm{~d}$ period. As is evident in this figure, although 


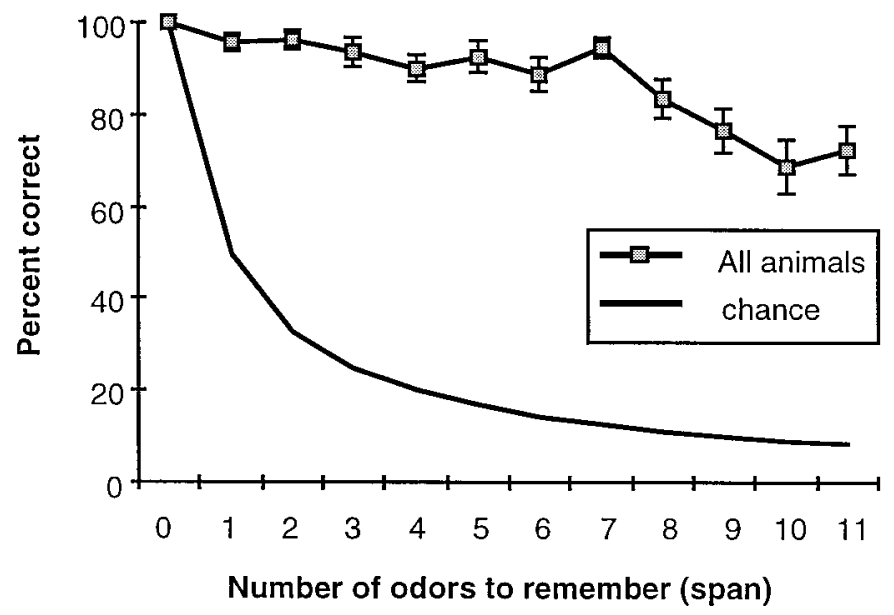

Figure 3. Percentage of correct responses as a function of the number of odors to be remembered for the $7 \mathrm{~d}$ period of training before surgery. Animals performed well above chance levels even when required to recognize up to 11 odors.

there was a decrease in accuracy with increasing spans $\left(F_{(11,165)}=\right.$ 10.44; $p<0.001$ ), performance of the task was significantly above chance levels at each span level tested (for spans $>0$, all $p$ values $<0.001)$. Thus, the span measure of Figure 2 does not appear to capture fully the animals' performance of this task; animals would make occasional mistakes during the series of 11 spans, but would often complete the remainder of the session without error. Their spans thus did not appear to reflect a memory load or capacity limit beyond which a significant performance decrement was observed.

\section{Probe sessions}

The results of the presurgery probe sessions suggest that the animals were indeed using the scent of the sand in making their discriminative response. In the no reward probe, the mean span $(8.56 \pm 0.66)$ did not differ from the average of each animal's median spans across the $7 \mathrm{~d}$ baseline period $\left(8.38 \pm 0.49 ; T_{(15)}=\right.$ $-0.237 ; p>0.81)$. Thus, the animals did not appear to be using the scent of the reward itself to guide their performance.

In the cup change probe, the mean span $(5.44 \pm 0.92)$ was significantly lower than the same average median baseline $\left(T_{(15)}\right.$ $=3.501 ; p<0.003)$. However, two observations qualify the interpretation of these results. First, in the presurgery cup change probe, only two animals had spans of 3 , and only two had spans of 7, indicating errors potentially associated with the first ( $\operatorname{span}=$ 4 ) and second ( $\operatorname{span}=8$ ) cup changes, respectively. The spans of the remaining 12 animals reflect first errors that did not occur immediately after the cups were switched. Second, when this probe was replicated after surgery, no effect of changing the cups was observed (see below). A potential difference between the presurgery probe and the postsurgery probe was that in the former, the odor and sand mixture was made up separately for each replacement cup, and thus the scents in the replacement cups may have differed slightly from initial cups in their intensity. In the postsurgery probe, care was taken to mix each odor and sand in a batch before distributing it among the multiple cups used for each odor.

\section{Hippocampal lesions}

Figure 4 is a representative photomicrograph of the lesion extent (Fig. 4A), and a reconstruction of the largest and smallest lesions
(Fig. 4B) on to standardized sections (based on Swanson, 1992). As is evident in the photomicrograph and schematics, the injections of ibotenic acid produced a complete loss of cells in all subfields of the hippocampus proper. In addition, in some cases the lesion encroached on the dorsal and ventral subiculum, as well as the anterior portions of the medial and lateral entorhinal cortex or the cortex overlying the dorsal hippocampus. In one animal, a small amount $(<10 \%)$ of CA1 was spared unilaterally.

\section{Postsurgery performance}

The control and hippocampal groups readily reacquired the nonmatching to sample rule after surgery. The control animals made an average of only $1.29( \pm 0.36)$ errors, and the hippocampal animals made an average of only $1.36( \pm 0.38)$ errors, before reaching criterion level of $80 \%$ correct on $2 \mathrm{~d}$ (eight trials per day). These averages were not significantly different $\left(T_{(13)}=0.17\right.$; $p>0.43)$.

The performance of control and hippocampal animals during the $7 \mathrm{~d}$ postsurgery testing period on the 12-odor span task is shown in Figure 5. As is evident from the figure, both groups performed well above chance at all span lengths $>0$ (all $p$ values $<0.001$; the control group's scores at span 1 could not be tested because they did not vary). The two groups did not differ in their percentage of correct responses $\left(F_{(1,13)}=0.92 ; p>0.76\right)$. The percentage of correct responses was influenced by span length $\left(F_{(11,143)}=3.543 ; p<0.001\right.$; linear trend, $p<0.001$; quadratic trend, $p<.048)$, but no interaction between groups and span length was observed $\left(F_{(11,143)}=0.673 ; p>0.76\right)$. On the span measure, there was no overall difference in performance between the control and hippocampal groups $\left(F_{(1,13)}=0.01 ; p>\right.$ $0.92)$, nor did spans differ across the $7 \mathrm{~d}$ period $\left(F_{(6,78)}=0.99 ; p>\right.$ $0.44)$. Differences in group performance did not vary significantly across the $7 \mathrm{~d}$ of testing $\left(F_{(6,78)}=0.47 ; p>0.83\right)$.

\section{Postsurgery probe sessions}

In the no reward probe session, the average span for the control group was $9.14( \pm 1.39)$ and for the hippocampal group was 8.75 $( \pm 1.40)$ These scores did not differ significantly $\left(T_{(13)}=0.199\right.$; $p>0.42)$. Because the groups did not differ, they were together compared to the final day of rewarded span testing (e.g., the seventh day). The span measure on this day across all animals was $9.4( \pm 0.72)$, and no difference between performance on this rewarded session and the no reward session was observed $\left(T_{(14)}=\right.$ $0.864 ; p>0.41)$. This result indicates that animals were not using the scent of the buried reward to solve the task after surgery.

In the cup change probe session, the average span of the control group was $8.29( \pm 1.17)$, and that of the hippocampal group was $7.63( \pm 1.02)$. These scores did not differ significantly $\left(T_{(13)}=\right.$ $-0.429 ; p>0.68)$. The performance of the animals on the cup change probe session did not differ from that on the final day of span testing where cups were not switched $\left(T_{(14)}=0.795 ; p>\right.$ $0.44)$. Because the average spans of the two groups were well above the point at which the first cup change took place (with the addition of odor 5; span length $=4$ ) and did not differ from the final day of span testing, it does not appear that the animals were relying on any marking of the odor cups or the sand itself to solve the task.

Because both control and hippocampal animals performed the task at significantly above chance levels, even with 11 odors to remember, it is possible that the task did not require a sufficient memory load to reveal a lesion impairment. To test this, we ran a 25-odor span probe session in which the animals were required to 

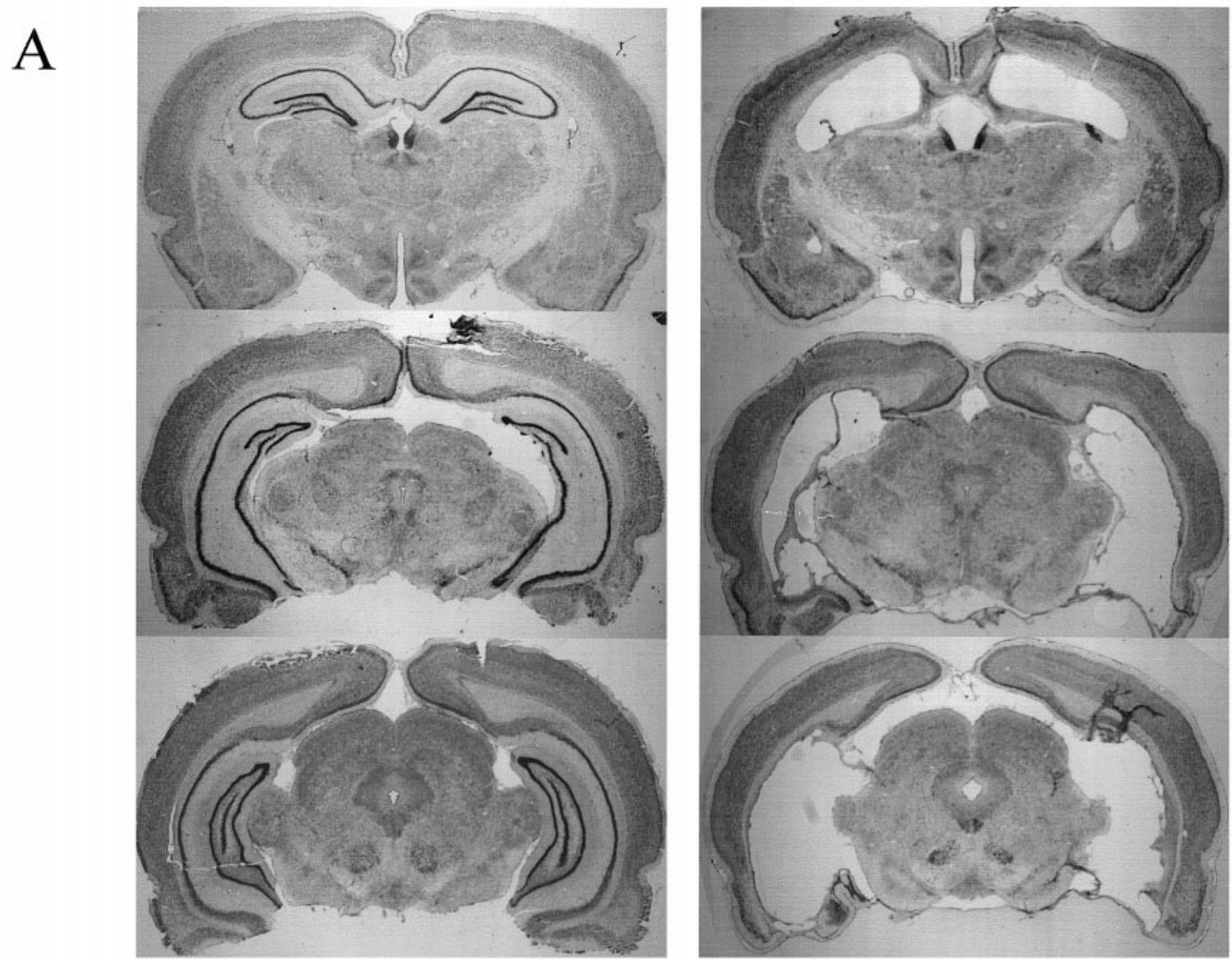

B

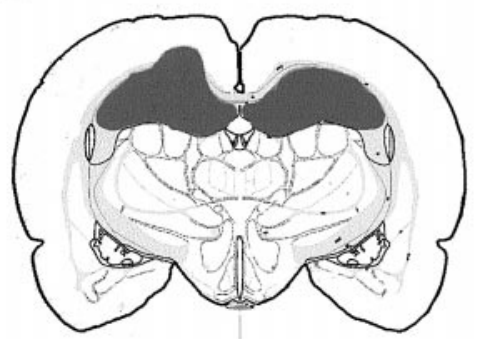

Smallest lesion
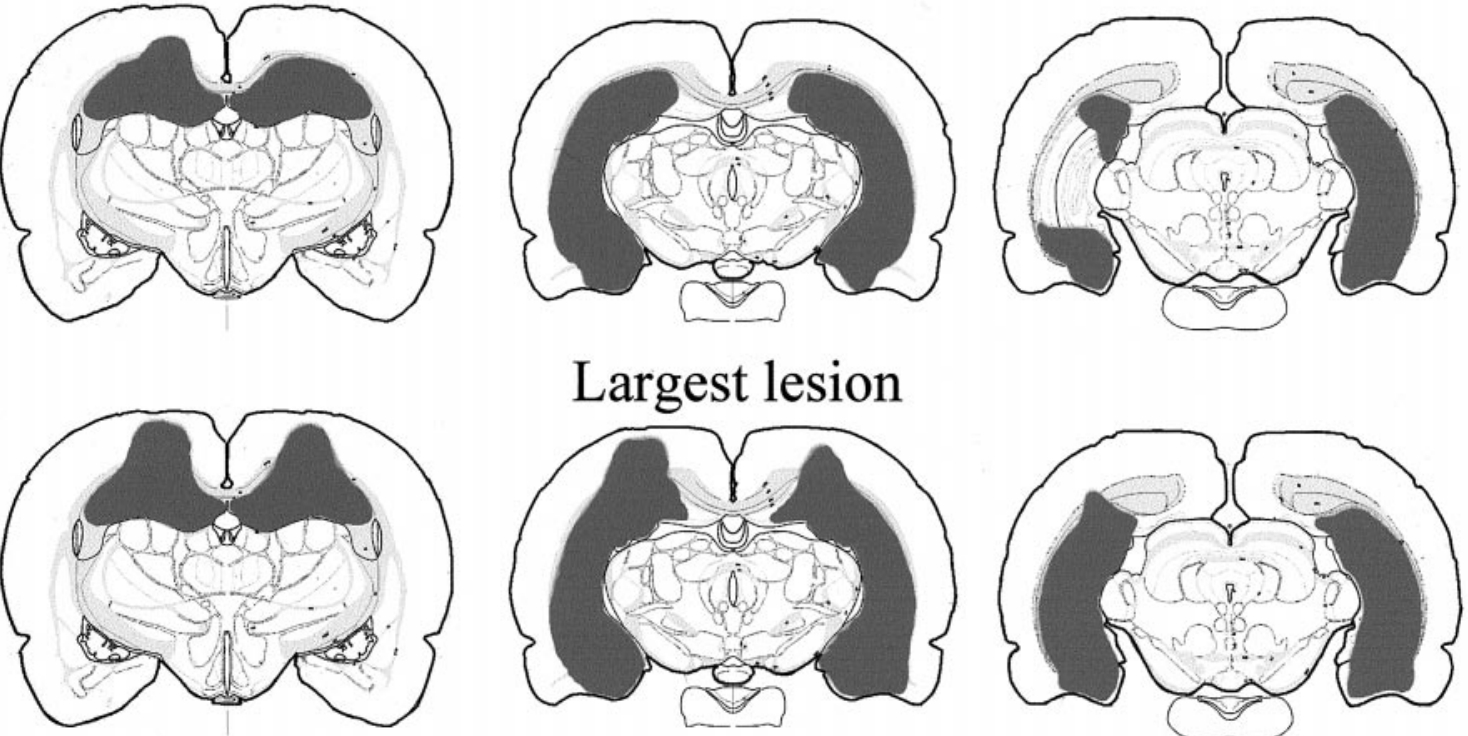

\section{Largest lesion}
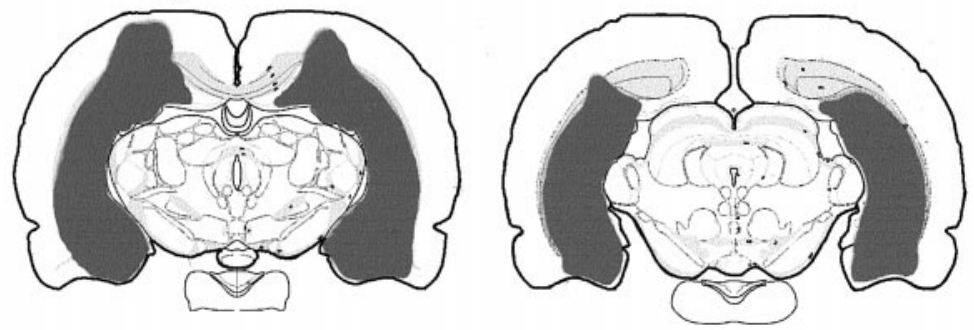

Figure 4. A, Photomicrographs of control (left) and hippocampal (right) brains at three sections through the hippocampus. B, Reconstruction of smallest and largest lesion extents.

remember up to 24 odors. The results of this probe session, run twice for every animal, are shown in Figure 6. To compare performance as the memory demand increased, the accuracy on successive blocks of five odors across the 25 odor series was measured. The control and hippocampal animals did not differ in the number of correct responses over each block of five spans $\left(F_{(1,13)}=0.106 ; p>0.75\right)$, nor did group performance differ across blocks (group $\times$ block interaction: $F_{(4,52)}=1.93 ; p>0.12$ ). 


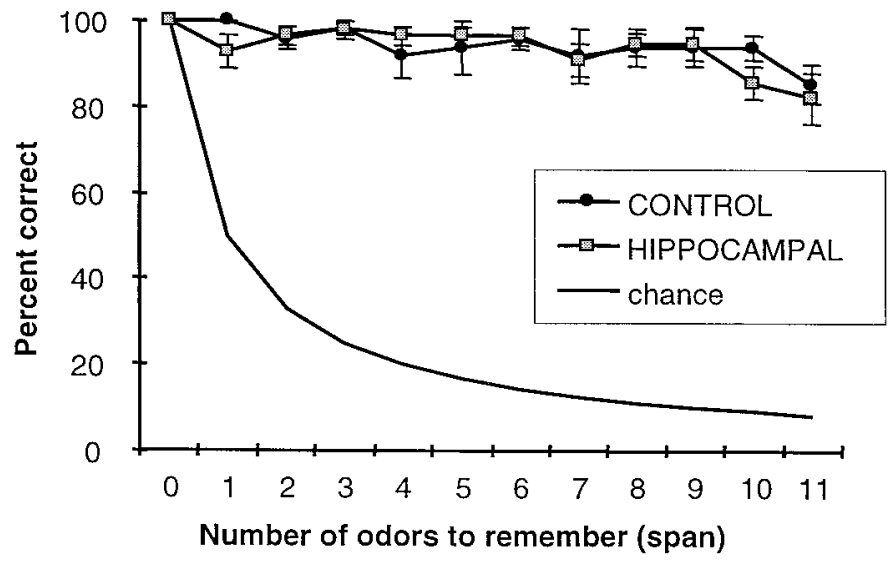

Figure 5. Percentage of correct responses for the control and hippocampal groups at each span length across the $7 \mathrm{~d}$ postsurgery testing period in the 12-odor span task.

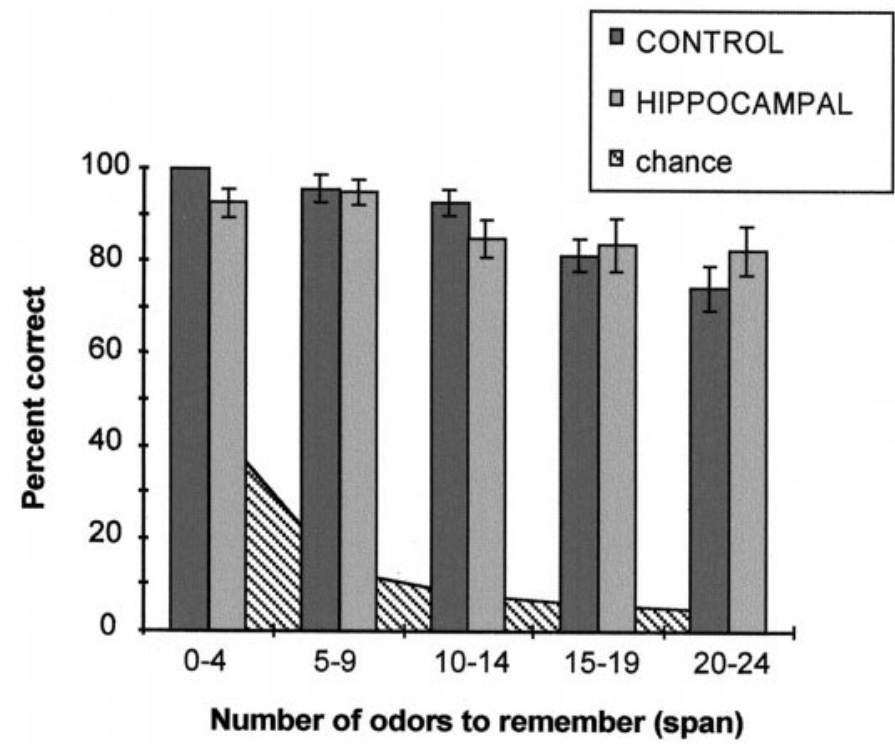

Figure 6. Percentage of correct responses for the control and hippocampal groups in the 25-odor span probe session. Spans (number of odors to be remembered) are shown in blocks of five.

A significant main effect of span length (in blocks of five spans) was observed $\left(F_{(4,52)}=10.2 ; p<.001\right.$; linear trend, $F_{(1,13)}=32.0$; $p<0.001)$. Thus, no impairment was observed when animals were required to remember up to 24 odors, although overall performance declined linearly with increasing span length.

\section{Odor delayed nonmatching to sample}

The performance of the control and hippocampal animals on the delayed nonmatching to sample task is shown in Figure 7. Both groups performed the task with $>80 \%$ correct accuracy at the 15 min delay, and the two groups did not differ from chance performance $\left(50 \%\right.$ correct) at the $3 \mathrm{hr}$ delay (control group, $T_{(6)}=1.55$, $p>0.17$; hippocampal group, $\left.T_{(7)}=0.30, p>0.77\right)$. A two-way ANOVA revealed a main effect of delay $\left(F_{(3,39)}=25.06 ; p<\right.$ 0.001 ) and a trend toward a difference in group performance across delays $\left(F_{(3,39)}=2.75 ; p>0.055\right)$. However, there was no overall difference in performance between the groups $\left(F_{(1,13)}=\right.$ $1.10 ; p>0.31)$.

It may be argued that, because both groups did not differ from

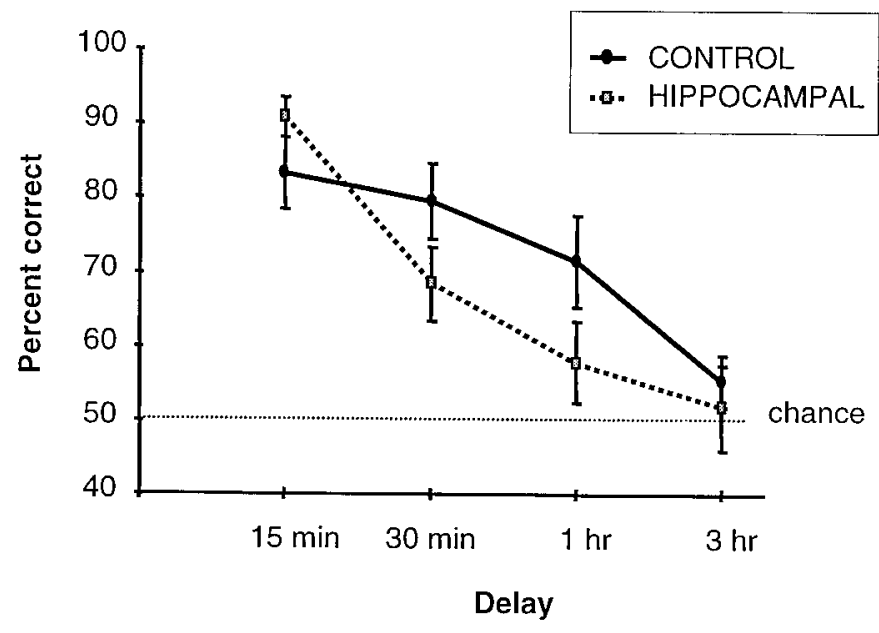

Figure 7. Percentage of correct responses for the control and hippocampal groups in the odor delayed nonmatching to sample task with 12 odors.

chance performance at the $3 \mathrm{hr}$ delay, the $3 \mathrm{hr}$ data point biases the statistical comparisons away from observing a difference between the control and hippocampal groups where such a difference may actually exist. To test this, an additional ANOVA was performed excluding the $3 \mathrm{hr}$ data point. No main effect of group was observed in this analysis $\left(F_{(1,13)}=1.32 ; p>0.27\right)$, although a significant interaction between groups and delays was observed $\left(F_{(2,26)}=3.63 ; p<0.04\right)$. This result suggests that the hippocampal group may have exhibited a small but significant impairment in memory for a list of odors with longer delays. Using the same logic, we reran this ANOVA without the $15 \mathrm{~min}$ data point and observed a marginal difference between control and hippocampal groups (group, $F_{(1,13)}=4.19, p>0.06$ ), and delay lengths (delay, $F_{(1,13)}=3.77, p>0.07$ ), but no interaction between groups and delay lengths $\left(F_{(1,13)}=0.07 ; p>0.80\right)$.

Post hoc comparisons of the two groups at each delay failed to reach significance $\left(15 \mathrm{~min}, T_{(13)}=-1.39, p>0.19 ; 30 \mathrm{~min}, T_{(13)}\right.$ $\left.=1.55, p>0.15 ; 60 \mathrm{~min}, T_{(13)}=1.65, p>0.12\right)$. However, comparisons of each group to chance performance (50\% correct) revealed that the control group was significantly above chance at the 60 min delay $\left(T_{(6)}=3.42 ; p<0.014\right)$, whereas the performance of the hippocampal group was not $\left(T_{(7)}=1.46 ; p>0.18\right)$.

\section{Alternation on the T-maze}

To test whether the lesions were sufficient to produce deficits on a different type of recognition memory, we assessed both groups of animals on a forced-sample T-maze alternation task. This task has a memory demand similar to that of the odor nonmatching to sample task, in that the animal has to remember what it has sampled, in this case a specific maze arm, and then select the alternative option, the other arm. Performance of control and hippocampal groups on this task is shown in Figure 8A. Each data point in the figure represents performance across a block of three daily sessions (six test trials per session). The performance of the hippocampal animals did not differ from chance (nine correct) at any of the four blocks of training (block $1, T_{(7)}=0.146, p>0.88$; block 2, $T_{(7)}=-1.0, p>0.35$; block $3, T_{(7)}=0.168, p>0.87$; block $\left.4, T_{(7)}=2.023, p>0.08\right)$. Their performance differed significantly from the control animals $\left(F_{(1,12)}=17.27 ; p<0.001\right)$. A main effect of training block was also observed $\left(F_{(3,36)}=3.88\right.$; $p<0.017)$, but the magnitude of this effect did not differ across groups (group $\times$ block interaction, $F_{(1,12)}=0.92, p>0.36$ ). 


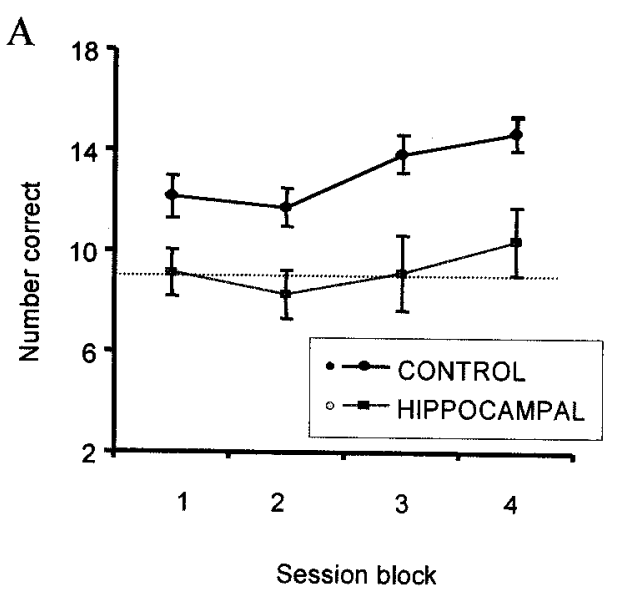

We were curious whether the robust impairment exhibited by the hippocampectomized animals was related to the "forced" presentation of the sample arm. Would the animals be better able to remember which arm they visited if allowed to choose the sample arm freely? To test this, we ran both control and hippocampal animals for an additional nine sessions (three blocks) on a free-sample T-maze alternation task. The task was run in a similar manner to the forced-sample version, except that during the sample phase, both arms of the $\mathrm{T}$ were open, and the animal was free to choose either as the sample arm. After the $15 \mathrm{sec}$ delay, the animal was again permitted to choose from the two arms of the T, but only the arm that had not been selected in the sample phase was reinforced. The performance of the two groups is shown in Figure $8 B$, blocks 5,6 , and 7. Block 8 is the data from trials in which animals were retested on the forced sample version of the task for an additional three sessions.

Animals with hippocampal lesions appeared to be worse than control animals in the free-sample version of the task (Fig. $8 B$, error bars; blocks 5-7), but surprisingly this difference was not significant (group effect, $F_{(1,13)}=2.21, p>0.16$; block effect, $F_{(2,26)}=0.351, p>0.71$; group $\times$ block interaction, $F_{(2,26)}=$ $0.401, p>0.93)$. One potential reason for this is that the scores of the animals in both groups exhibited more variability in this version of the task. This variability appeared to be attributable to a nonrandom distribution of scores; many animals had scores well below chance levels, whereas others had scores above chance levels. This is evident in the average score of each animal across the free-sample sessions (Fig. $8 B, A v g$.). Inspection of the distribution of correct and incorrect responses for each group suggested that individual animals were biased toward one or the other side of the maze when performing the free-sample task. Individual control animals typically chose the same arm (e.g., the right arm) during the sample run, and then would alternate appropriately in the choice run. Individual hippocampal animals would likewise tend to choose a specific arm during the sample run, but would tend to choose the same arm again during the choice run.

\section{Summary}

The current results reveal that rats are able to recognize up to 24 previously presented odors accurately within a testing session, and that the hippocampus is not necessary for this kind of recognition memory. The results of the probe sessions suggest that the animals used the scents added to the sand, and not the scent of the reward itself or markings on the cups or sand, to solve the task. Testing in a delayed olfactory nonmatching to sample task yielded a small but significant deficit that depended on the delay, suggesting that the hippocampus may be necessary for full expression of odor recognition memory at longer delays. Subsequent assessment in a delayed alternation T-maze revealed a robust deficit in performance comparable to that reported previously after hippocampal (Aggleton et al., 1986) or fornix (Neave et al., 1994) lesions.

\section{EXPERIMENT 2: SPATIAL SPAN TASK}

In experiment 1 the observation of intact memory for multiple nonspatial items stands in marked contrast to the impairment in spatial memory on the T-maze. An obvious difference between the two tasks is that the T-maze taxes memory for spatial locations, whereas the odor span and delayed nonmatch to sample tasks tax memory for nonspatial, olfactory stimuli. Indeed, much of the available behavioral data from animals is consistent with the hippocampus being required for spatial tasks, but not for nonspatial tasks. However, there are exceptions to this general rule.

First, deficits in performance on several nonspatial learning and memory tasks have been observed with fimbria-fornix or hippocampal damage (Olton and Feustle, 1981; Rawlins et al., 1993; Bunsey and Eichenbaum, 1996; Dusek and Eichenbaum, 1998; Clark et al., 1999). Success in performance on many of these nonspatial learning and memory tasks depends on the experimental protocol or the way in which memory is assessed (Eichenbaum et al., 1988).

Second, performance on some spatial tasks is not disrupted by hippocampal damage (Whishaw et al., 1995; Murray and Mishkin, 1998). There may be multiple aspects of spatial memory performance, and it has been suggested that the hippocampus may be required for only some of these abilities (Whishaw et al., 1995). Specifically, Whishaw et al. (1995) have argued that the hippocampus is necessary for navigation between spatial locations ("getting there"), but not for remembering the spatial location of reinforcement based on ambient cues, or for recognizing such a spatial location ("knowing where"). Most spatial memory tasks for rats, including the T-maze spatial alternation task used in experiment 1 , involve both of these abilities; they require that an animal remember recent visits to a location (knowing where), and remember how to get to either the same or a different location based on this information (getting there). This distinction might explain the lack of impairment observed in monkeys with hippocampal lesions on a spatial recognition memory task in which 


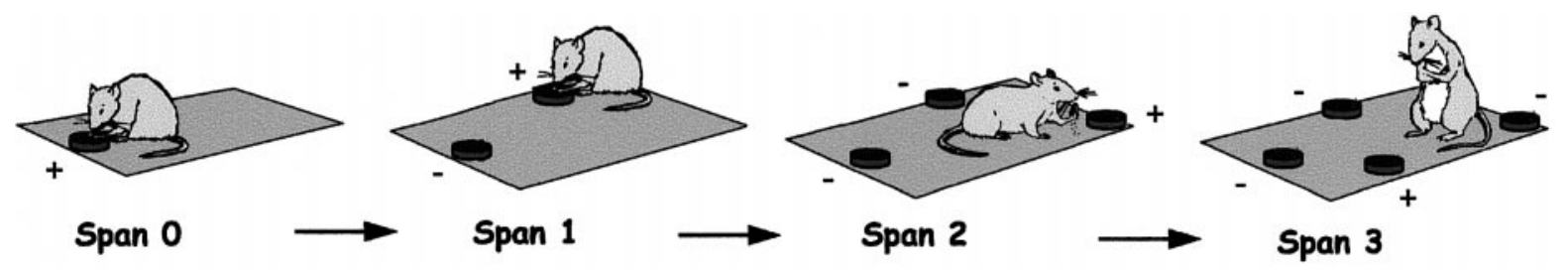

Figure 9. Schematic of the spatial span task. An animal was presented with an unscented cup of sand in a specific location on the platform. After retrieving the buried reward, the animal was removed from the platform, and a second cup of sand was added in a different location. The animal's task, on its return to the platform, was to remember the location of the cup that it had already sampled and select the cup in the new location. Additional cups in additional locations were presented in the same manner.

navigation is not required (Murray and Mishkin, 1998) (see also Maguire et al., 1999).

There are additional alternative explanations for the different effects of hippocampal lesions on performance of the T-maze task and the odor span task. First, training of the odor span task took place before surgery, whereas training of the T-maze alternation took place after surgery. Thus, the impairment on the T-maze may reflect a deficit in acquisition of the spatial memory rule, rather than a deficit in memory for places per se. Indeed, animals trained on a radial arm maze before removal of the hippocampus were able to perform this task after surgery, whereas animals trained only after surgery were impaired (Jarrard, 1993). Second, the T-maze alternation task may have been more difficult than the odor span or odor delayed NMS tasks because in the T-maze the pool of stimuli from which the animal must make a choice was only two, whereas in the odor tasks the stimulus pool consisted of 12 or 25 stimuli. Thus, interference between trials on the T-maze task may have made the task more difficult and thus more sensitive to hippocampal damage (Rawlins et al., 1993).

To clarify the pattern of results observed across tasks in experiment 1 , in experiment 2 we explored the contributions of the hippocampus to performance in a spatial version of the span task. This assessment permitted us to address whether the dissociation between the odor span task and the T-maze alternation was attributable to the effects of training before surgery, the level of interference, or differences in the testing procedures. This novel test also allowed us to examine memory for spatial locations in rats in a paradigm that did not require accurate navigation between locations for correct performance.

\section{Materials and methods}

Subjects. Subjects were 16 behaviorally naïve, male Long-Evans rats, weighing between 175 and $225 \mathrm{gm}$ at the beginning of training. Rats were housed, fed, and watered in the same way as the rats in experiment 1.

Shaping. Rats were trained and tested on the same Plexiglas platform used in experiment 1 . After handling, rats were shaped to dig in a cup of unscented playground sand (100 gm) for a single buried Froot Loop cereal reward.

Spatial nonmatching to sample. Once the animals readily dug for the buried reward, they were trained on a spatial NMS task. This task was similar to the odor NMS task, but here the animals were required to remember which location it had visited, and then to select a different choice location. Animals were first presented with a cup of unscented sand in one of 21 locations along the platform perimeter. After digging in the sand, the animal was removed from the platform and placed in an opaque bucket. The experimenter then replaced the sample cup with another cup of unscented sand in the same location and placed an additional cup in a new randomly selected location on the platform. Reinforcement was available only in the cup in the new location. As in the previous experiment, a choice was scored if the rat dug or placed its paws on the sand. Animals were given 12 NMS trials each day, until they selected the new location at least 9 of 12 times on three separate days. Varying the distance between cups in the choice phase of this task did not appear to produce any systematic difference in the animals' accuracy.
Spatial span task. Animals were then placed in the spatial span task shown in Figure 9. As in the odor span task, the spatial span was an extension of the NMS rule wherein additional samples were presented successively within each trial. Thus, after the animal made a correct response on the initial choice phase of the task, it was placed back in the opaque bucket, and an additional cup with unscented sand was added to the platform in a new location. The remaining cups on the platform were replaced as well, so that the animal could not solve the task by marking the cups. When returned to the platform, the animal was required to dig in the cup at the new location to obtain another buried reward. A cereal reward was buried in the sand of this cup. If the animal made a correct response, it was put back in the bucket, and yet another cup was added at a new location. If the animal dug in the cup at a previously presented location, the trial was terminated. In the first $11 \mathrm{~d}$ of spatial span training, animals were given between four and six trials per day.

Six-location span task. After this $11 \mathrm{~d}$ period, animals were given two trials per day with span lengths from 1 to 6 on each trial. This version of the task was similar to that just described, and the span was recorded in the same way. However, if an animal made an error, it was permitted to subsequently select the correct location. To test whether the distance between cups made the task easier or more difficult, in one of the trials the cups were placed at adjacent locations, whereas in the second trial, the distance between added cups was maximized.

Twelve-location span task. In the final version of the task, as in experiment 1 , animals were tested with spans from 1 to 11 (2-12 locations) for $7 \mathrm{~d}$ using random distances between cups. Again, animals were permitted to select the correct location after making an error, and thus all animals experienced all 11 span lengths.

Probe sessions. To verify that the animals were using the location of the cup and not any potential scent of reward to solve the task, animals were run on a no reward probe session. In this session, reward was available only after the animal made its response. This probe session was run for the fixed spans of 6 and 12 before surgery, and for the 12-location span afterwards.

Hippocampal lesions and postoperative training. After $7 \mathrm{~d}$ with the 12-location spans and the no reward probe sessions, performancematched animals were assigned to either the control or hippocampal conditions and underwent surgery as in experiment 1 . After a 2 week recovery period, animals were retrained on the NMS rule with two cups. They were trained in this phase of the task until they reached a criterion of at least 9 of 12 responses correct on $2 \mathrm{~d}$. On reaching this criterion, animals were placed back in the 12-location span task for $8 \mathrm{~d}$.

Spatial delayed nonmatching to sample. After assessment in the 12location span task, both groups of animals were tested in a spatial delayed NMS task. In this task, animals were placed on the platform with a cup of sand present in a randomly chosen location. Once the animal had dug in the sand and recovered a cereal reward, it was placed in an opaque bucket for a delay of $10 \mathrm{sec}, 1 \mathrm{~min}, 2 \mathrm{~min}$, or $5 \mathrm{~min}$. During the delay, the experimenter replaced the sampled cup with a different cup and added a second cup in a new location. After the delay, the animal was required to remember which location it had visited and select the location it had yet to visit. Only the cup in the new location contained a cereal reward.

Alternation on the platform and on a T-maze. One potential explanation for the robust impairment observed in the T-maze alternation task of experiment 1 is that interference associated with the small number of test locations makes the task particularly sensitive to hippocampal disruption. Another alternative is that the configuration of the T-maze apparatus itself may contribute in some unanticipated way to the deficit. To distinguish between these possibilities, we tested the current animals on an alternation task on the platform. 


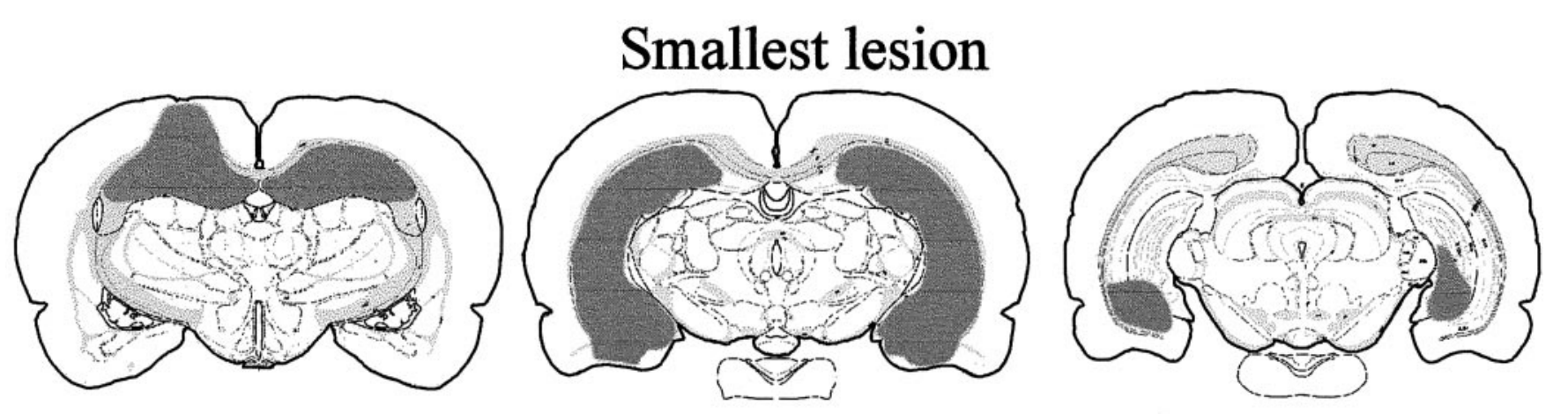

Largest lesion

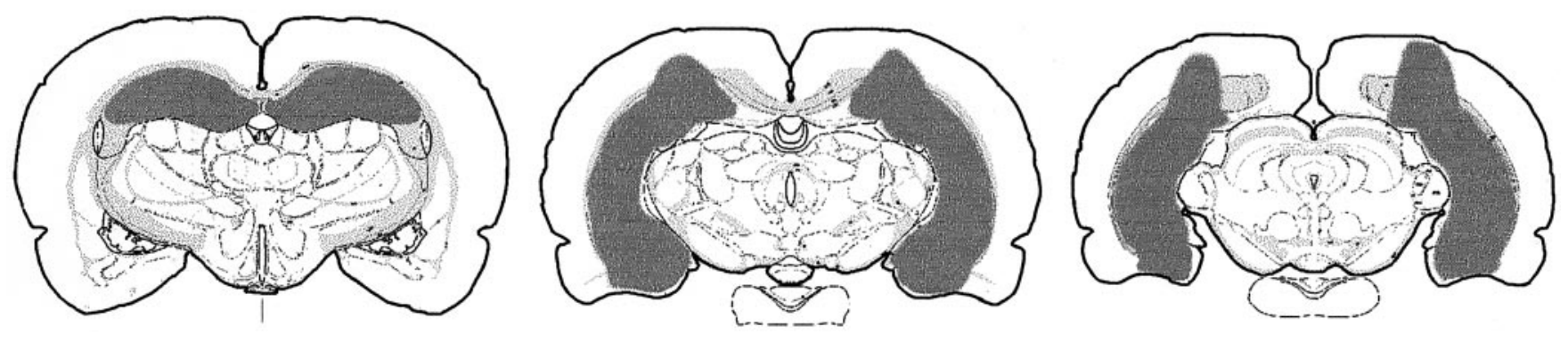

Figure 10. Reconstruction of smallest and largest lesion extents for experiment 2.

This task was identical to the delayed NMS task above, except that the same two corner locations on the platform were used on each trial. In the sample phase of the task, one location was occupied by a cup of sand containing a reward. In the choice phase, both locations had cups. The rats were rewarded only for digging in the cup of sand in the location not used in the sample phase. Rewards were dropped into the cups only after the animals dug, and the trial ended when the animal dug in either cup. Both locations served equally as the sample location. During the choice phase of the task, we recorded both the cup in which the animal dug and the first cup it approached. The interval between the sample and choice phase on each trial was $15 \mathrm{sec}$. Six trials were given per day, and rats were run in squads of four, so the intertrial interval was $\sim 5$ min. Rats were run for nine daily sessions. To test whether the animals were using the distal landmarks in the room to disambiguate the locations in this task, both groups were subsequently tested on the same task in a new room for three sessions of six trials.

Finally, both groups of animals were trained for nine sessions (six trials per session) on the alternation task in a T-maze. The task was run in the same way as the platform alternation task, and cups of unscented sand were located at the end of the maze arms. During the sample phase of the task, one arm was open, and the animal had to traverse it and dig in the cup of sand for a reward. In the choice phase, both arms were open, but rats were rewarded only for digging in the cup in the opposite arm. If the animal entered the incorrect arm but did not dig in the cup, it was allowed to turn and select the correct arm. The trial ended when the animal dug in either cup. Again, we recorded both the cup in which the animal first dug and the first arm it entered.

Histology. After completion of testing, animals were processed for histology in the same manner as experiment 1.

\section{Results}

Acquisition and preoperative performance of the spatial span task

Animals required an average of 11 sessions of training (range, 7-18) until they reliably selected the nonmatching cup location in the nonmatching phase of training. They were then placed in the spatial span task and were given as many trials as possible (typically between two and eight) in a 15-20 min daily testing period. As in experiment 1, animals were trained in this phase of the task until their performance stabilized and then moved to the fixed length versions of the span task.

\section{Six-location span task}

The average of each animal's median span across the $7 \mathrm{~d}$ presurgery testing was $2.0( \pm 0.18)$ when the cups were near each other and $1.88( \pm 0.26)$ when the distance between cups was maximized. These means did not differ $\left(T_{(15)}=-0.38 ; p>0.71\right)$. Thus, the task did not appear more difficult when the cups were close to each other, as opposed to when they were spread apart.

\section{Twelve-location span task}

The average of each animal's median span across the $7 \mathrm{~d}$ of presurgery testing on the 12-location spatial span task was 4.56 $( \pm 0.45)$. This was significantly lower than the average median span for animals in the odor span task $\left(T_{(30)}=-3.81 ; p<0.001\right)$. The increase in the median span scores in this version of the task over the 6-location version likely reflects the increased range of scores possible in the 12-location task. As characterized by median span length, the spatial span task was more difficult than the odor span task (see below).

\section{Probe sessions}

In the no reward probe session, the animals' spans did not differ significantly from the immediately preceding day when rewards were available in the cups (paired $t$ tests; six locations, cups clustered, $T_{(15)}=0.0, p<1.0$; spread apart, $T_{(15)}=0.96, p>$ $0.354 ; 12$ locations, $\left.T_{(15)}=-1.46, p>0.17\right)$. Thus, it did not appear that the animals were using any scent from the reward itself to guide their performance in the task.

\section{Hippocampal lesions}

Figure 10 presents a reconstruction of the largest and smallest lesions. Injections of ibotenic acid produced a complete loss of 


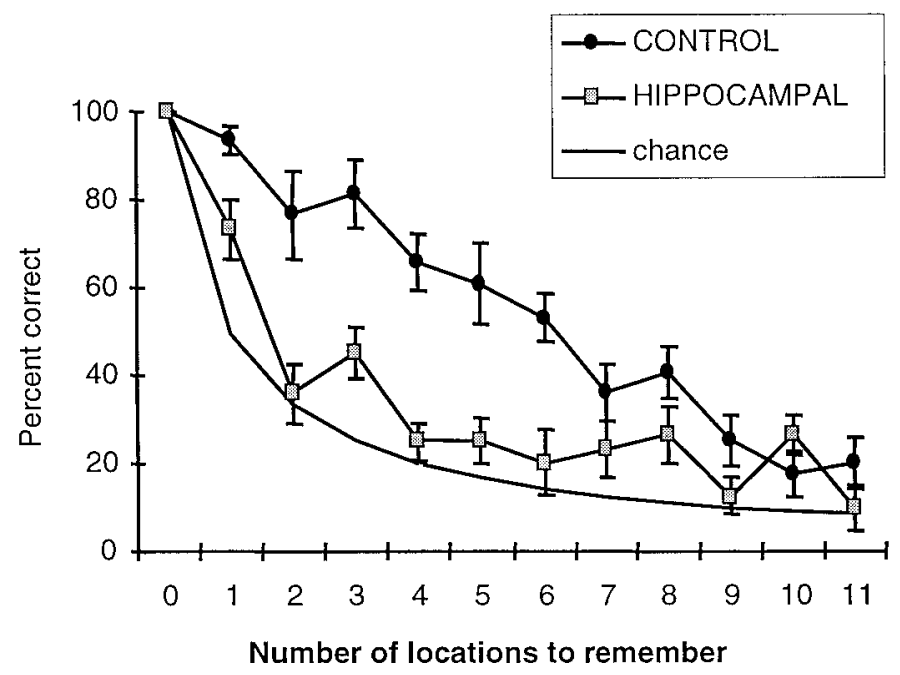

Figure 11. Percentage of correct responses for the control and hippocampal groups at each span length across the $7 \mathrm{~d}$ postsurgery testing period in the 12-location span task.

cells in all subfields of the hippocampus proper for the majority of animals. In all animals, the anterior-dorsal hippocampal lesion was complete. However, in three animals a small extent of the posterior-most region of CA1 and the dentate gyrus was spared. Damage to ventral subiculum and medial and lateral entorhinal cortices was observed near the ventral-most injection sites.

\section{Postsurgery performance}

The hippocampal group made significantly more errors (43.6 \pm $10.0)$ than the control group $(7.6 \pm 3.7)$ before reacquiring the nonmatching-to-sample rule to the criterion level $\left(T_{(14)}=-3.39\right.$; $p<0.001)$. Subsequent performance of the two groups in the 12-span task over the $7 \mathrm{~d}$ postsurgery testing period is shown in Figure 11. As is evident in the figure, the hippocampal group was significantly impaired relative to the control group $\left(F_{(1,14)}=\right.$ $26.88 ; p<0.001)$. The accuracy of both groups decreased as the number of locations to remember increased $\left(F_{(11,154)}=44.17 ; p<\right.$ $0.001)$. Group performances differed across span lengths $\left(F_{(11,154)}\right.$ $=4.41 ; p<0.001)$, with the control group performing significantly better than the hippocampal group on spans 1-6 (independent sample, group $t$ tests for each span, all $p$ values $<0.05)$, but not differing on spans 7-11 (all $p$ values $>0.1$ ). The performance of the hippocampal group was significantly better than chance at spans of $1,3,8$, and 10 (all $p$ values $<0.05$ ), however it did not differ from chance at spans of 2, 4, 5, 6, 7, 9, and 11 (all $p$ values $>$ 0.14 ). Because it is unlikely that the animals can remember three items but not two, significant differences from chance at spans $>2$ may not be meaningful. The three animals of the hippocampus group with a small amount of sparing in the posterior-ventral regions did not differ significantly from the remainder of the group in the 12-span task $\left(F_{(1,6)}=0.23 ; p>0.65\right)$, and they were thus considered together in the above and subsequent analysis.

Performance was also evaluated by calculating the number of locations correctly chosen before an error (the span). Across the $7 \mathrm{~d}$ postsurgery testing period, the control group had an average median span of $3.31( \pm 0.53)$, whereas the hippocampal group had an average span of only $1.06( \pm 0.17)$. Comparison of the spans of the two groups across the $7 \mathrm{~d}$ testing period revealed a significant difference $\left(F_{(1,14)}=13.83 ; p<0.002\right)$. Spans did not differ significantly across days $\left(F_{(6,84)}=0.62 ; p>0.72\right)$, and the mag-

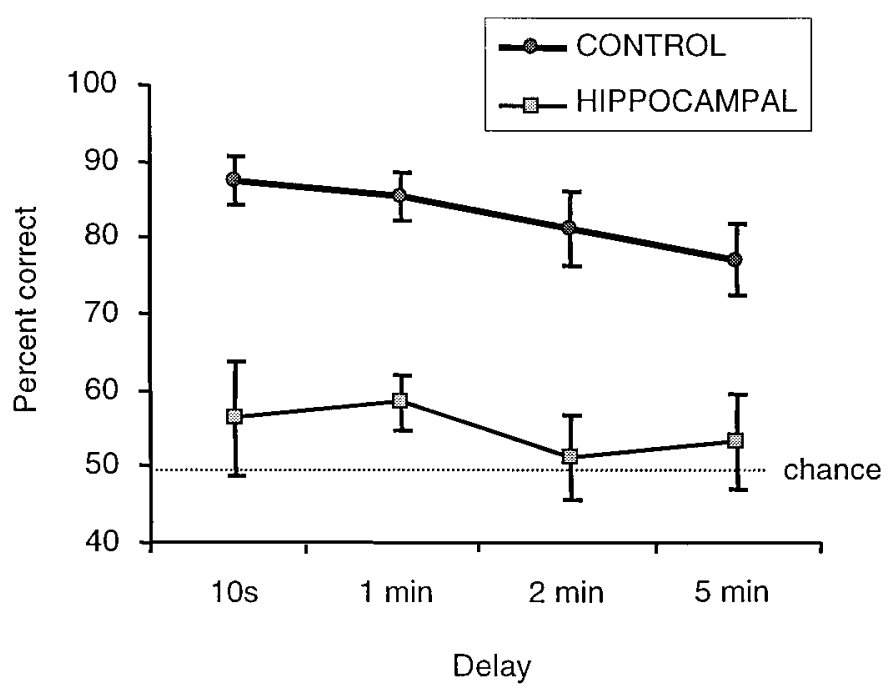

Figure 12. Percentage of correct responses for the control and hippocampal groups in the spatial delayed nonmatching to sample task.

nitude of the impairment did not differ across days (group $\times$ day interaction, $\left.F_{(6,84)}=0.70, p>0.65\right)$. Additionally, there was no difference between group performance on the final session of 12 -span testing with reward and a subsequent no reward probe session $\left(T_{(15)}=-0.57, p>0.58\right)$, suggesting that the animals were not relying on the scent of the buried reward to guide their responses.

\section{Spatial delayed nonmatching to sample}

The performance of the control and hippocampal animals on the spatial delayed nonmatching to sample task is shown in Figure 12. A two-way ANOVA revealed a significant overall difference between the control and hippocampal groups $\left(F_{(1,14)}=45.77 ; p<\right.$ $0.001)$, but no effect of delay length $\left(F_{(3,42)}=1.17 ; p>0.33\right)$ and no difference in the magnitude of impairment across delays (group $\times$ delay length interaction, $\left.F_{(3,42)}=0.24, p>0.87\right)$. The hippocampal group's performance did not differ from chance (six correct) at delays of $10 \mathrm{sec}, 2 \mathrm{~min}$, or $5 \mathrm{~min}$ (all $p$ values $>0.4$ ), although it did rise above chance at the 1 min delay $(p<0.05)$.

\section{Alternation on the platform}

The performance of control and hippocampal animals across 12 sessions of testing, grouped in blocks of three sessions, is shown in Figure 13. Because it has been previously suggested that hippocampus is necessary for guidance of movement toward a goal location, rather than recognition of the location itself (Whishaw et al., 1995), we recorded both the first cup location that the animal approached and the first cup location at which it dug. An approach was scored if the animal moved directly toward a cup, and a dig was scored if the animal touched the sand with its paw or snout. The first three blocks of testing took place in the same room as the spatial span training, and these data were the subject of one analysis, whereas the fourth block was run on the same platform placed in a new room and was analyzed separately.

A three-way ANOVA was run to compare the differences between experimental groups (hippocampal vs control), within groups across blocks of sessions, and within animals between dependent measures of performance (digging vs approaching). Two results from this analysis were of particular interest. First, across the first three blocks of testing, the hippocampal group was 


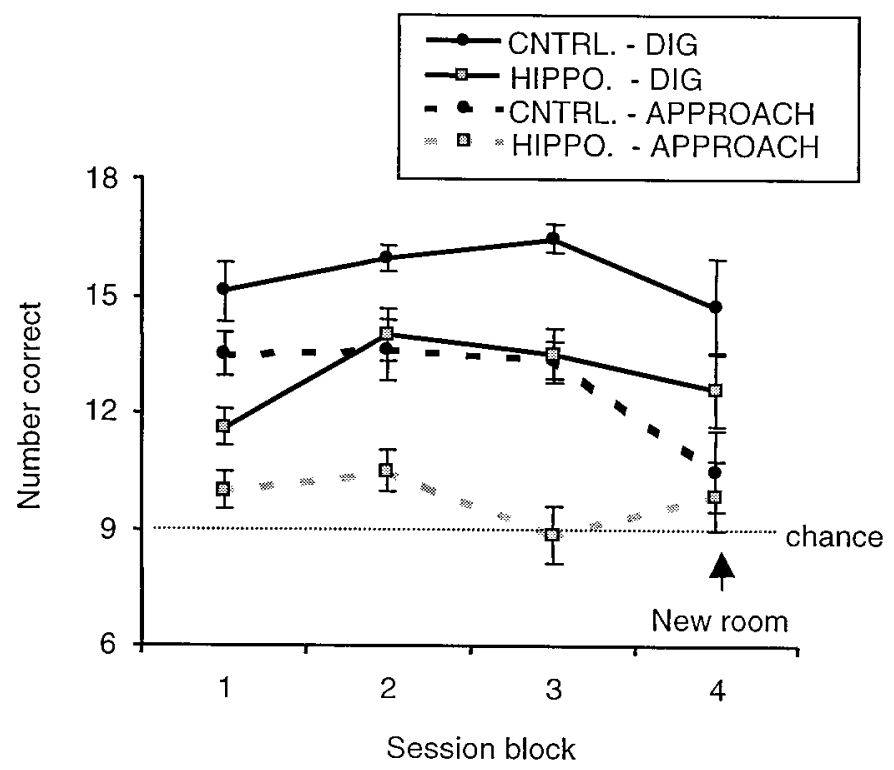

Figure 13. Number of correct responses for the control (CNTRL.) and hippocampal (HIPPO.) groups on the delayed alternation task on the open platform. Two dependent measure of performance were recorded: the first cup approached by the animals (Approach) and the first cup in which the animal dug (Dig). Animals were tested for three blocks of four sessions ( 6 trials per session) in the familiar testing room, and then were tested for one block of four sessions in a new room.

significantly impaired relative to the control group $\left(F_{(1,14)}=\right.$ $61.47 ; p<0.001)$. Second, there was a significant difference in the accuracy of the animals' performance as measured by the first cup approached as opposed to the first cup to which a digging response was made $\left(F_{(1,14)}=87.44 ; p<0.001\right)$. Performance did not vary significantly across blocks of sessions $\left(F_{(2,28)}=1.83 ; p>\right.$ 0.17 ), and there were no significant interactions between experimental groups and sessions $\left(F_{(2,28)}=0.76 ; p>0.48\right)$, between experimental groups and dependent measures $\left(F_{(1,14)}=2.12 ; p>\right.$ $0.16)$, or between the three factors together $\left(F_{(2,28)}=1.23 ; p>\right.$ $0.31)$. The only interaction to achieve significance was that between the two different measures of performance across blocks of sessions $\left(F_{(2,28)}=10.30 ; p<0.001\right)$, suggesting that performance according to the two measures did not vary in the same way across blocks of sessions.

The hippocampal group's performance, as assessed by the approach measure, did not differ from chance on blocks $1\left(T_{(7)}=\right.$ $2.16 ; p>0.06)$ or $3\left(T_{(7)}=-0.174 ; p>0.86\right)$, although a small but significant difference was observed on block $2\left(T_{(7)}=2.806\right.$; $p<0.026)$. In contrast, when one considers the first-dig measure, the hippocampal group's performance was well above chance levels on all blocks (block $1, T_{(7)}=5.7, p<0.001$; block $2, T_{(7)}=$ 7.338, $p<0.001$; block 3, $\left.T_{(7)}=6.464, p<0.001\right)$.

Separate two-way ANOVAs were run to assess the effects of testing in a new room. We compared the number of correct responses on the final block of three sessions in the old room to the number of correct responses on the block of three sessions run in the new room. Moving to a new room did not significantly affect overall performance $\left(\mathrm{dig}, F_{(1,14)}=2.21, p>0.16\right.$; approach, $\left.F_{(1,14)}=1.38, p>0.26\right)$, and although no interaction between experimental group and room was observed when the dependent measure was the first cup in which a dig response was made $\left(F_{(1,14)}=1.53 ; p>0.63\right)$, an interaction between group and room was found when the first cup approached was the measure con-

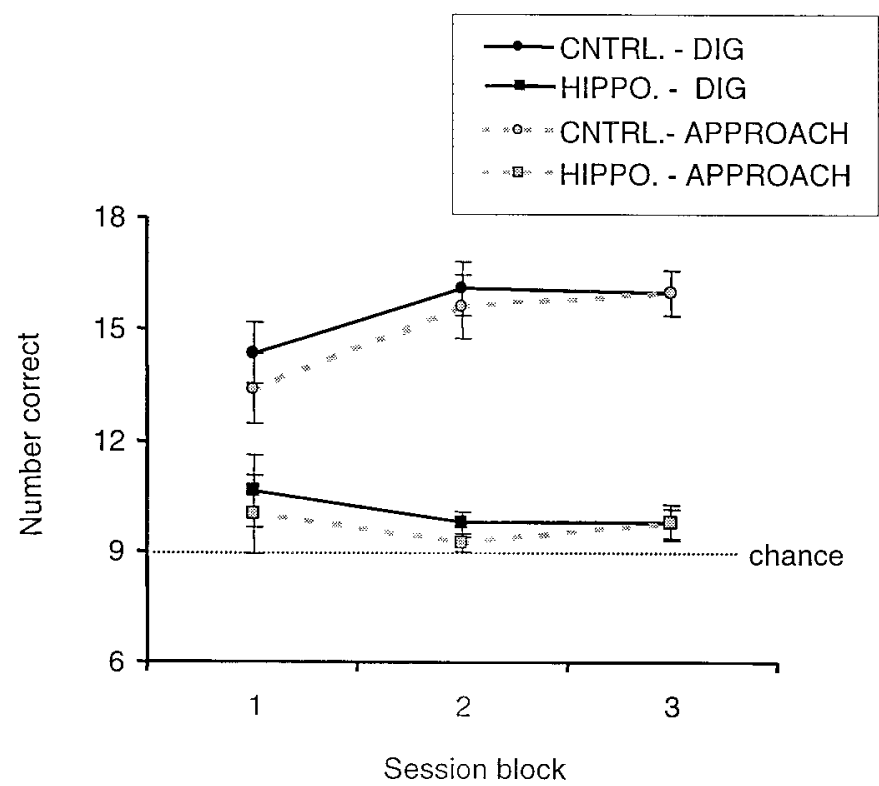

Figure 14. Performance of control and hippocampal groups on the T-maze delayed alternation task. Blocks of four sessions (6 trials per session) are shown. As in Figure 13, approach and dig responses were recorded.

sidered $\left(F_{(1,14)}=5.89 ; p<0.03\right)$. This interaction appeared to be attributable to a decrease in the control group's performance to the same level as the hippocampal group in the new room (Fig. 13, dashed lines, blocks 3 and 4). The control group performed significantly better than the hippocampal group in the old room on block $3\left(T_{(14)}=5.28 ; p<0.001\right)$, but performance by the two groups did not differ in the new room (block $4, T_{(14)}=0.46, p>$ $0.65)$.

\section{Alternation on the T-maze}

The data from both groups of animals across three blocks of sessions (six trials per session, three sessions per block) is shown in Figure 14. As in experiment 1, the hippocampal group was significantly impaired relative to the control group $\left(F_{(1,14)}=\right.$ 51.72; $p<0.012)$. There was no main effect of session block $\left(F_{(2,28)}=1.05 ; p>0.36\right)$, although an interaction between session block and experimental group did reach significance $\left(F_{(2,28)}=\right.$ $3.98 ; p<0.03)$. A small but significant difference was also observed between the first dig measure and the first approach measure $\left(F_{(1,14)}=8.23 ; p<0.012\right)$, and this difference interacted with session block $\left(F_{(2,28)}=3.38 ; p<0.048\right)$. No interaction between measures of performance and experimental group $\left(F_{(1,14)}=0.17 ; p>0.69\right)$, or between these variables and session block $\left(F_{(2,28)}=0.24 ; p>0.79\right)$ was observed. This result suggests that on the T-maze animals may have had more of a tendency to make their arm choice and digging responses together in a relatively fixed manner.

Is the spatial span task more difficult than the odor span task? Finally, because the odor and spatial spans tasks were run in identical ways, we were able compare the performance of the control groups in each experiment to address this question. An ANOVA on the percentage of correct responses at each span length for the $7 \mathrm{~d}$ testing period for the two control groups (after the sham surgeries) revealed a highly significant difference between their performance in the odor and spatial span tasks 
$\left(F_{(1,13)}=88.67 ; p<0.001\right)$. This difference between tasks depended on span length (task $\times$ span length interaction, $F_{(11,143)}=$ $13.28, p<0.001)$. Post hoc comparisons of the two control groups at each span length $>0$ suggest that this interaction was attributable to similar performance on spans 1-3 of each task ( $p$ values $>$ 0.07 ), and a significant difference on spans $4-11$ (all $p$ values $<$ 0.02). Thus, the spatial span task appeared to become more difficult than the odor span task when more than three locations were to be remembered.

\section{DISCUSSION}

The recognition memory capacity of normal and hippocampectomized animals was assessed in novel tests in which (1) the number of items to be remembered, and (2) the delay over which items must be held in memory was varied. Normal rats demonstrated an impressive capacity of memory for odors, remembering $>90 \%$ of lists of 10 items and nearly $80 \%$ of a list of 25 items. Hippocampectomized rats performed as well as normal rats on the odor span task, even with the longest lists. The performance of hippocampectomized rats on an odor nonmatching to sample task was modestly but significantly impaired, depending on the delay. By contrast to their modest impairment in odor memory capacity, hippocampectomized rats exhibited robust impairments in their capacity for spatial memory in several tests, although these rats could remember a single location by some measures. These results are considered below.

\section{Intact odor span performance with hippocampal lesions}

The results of experiment 1 are consistent with the lack of impairment observed on nonmatching to sample tasks in rats with fornix or hippocampus lesions (Aggleton et al., 1986; Mumby et al., 1992; Otto and Eichenbaum, 1992), and in hippocampectomized monkeys on lists of up to 40 objects (Murray and Mishkin, 1998). The combination of these results suggest that some forms of recognition memory are independent of the hippocampus. This view is consistent with Aggleton and Brown's (1999) recent hypothesis that the perirhinal cortex and medial thalamus, as opposed to the hippocampus, are necessary for recognition memory or familiarity judgments with nonspatial cues.

The significant delay by lesion interaction observed in the odor nonmatching to sample task however, does not preclude the possibility that the hippocampus is necessary for nonspatial recognition memory at longer delays. Indeed, small but significant deficits have been observed with hippocampectomized monkeys in NMS tasks (Zola et al., 2000) and in rats performing a delayed spontaneous recognition task (Clark et al., 1999). In the span tasks, the delays between each increasing span length were on the order of 10-20 sec, and the presentation of all 11 spans usually occurred within $15 \mathrm{~min}$. Thus, one potential reason that deficits were not evident in the odor span task is that memory for the increasing array of odors occurred within a delay that did not tax the hippocampal system.

Although the procedures of our span tasks were similar to those of Beason-Held et al. (1999), we observed different results. Whereas they found impairments in color, object, and spatial span tasks, we observed an impairment only in a spatial span task. One possible interpretation of this (discussed below) is that the hippocampus is specifically involved in spatial memory in the rat but participates in many types of memory in the primate. Another possibility lies in the different ways in which the tasks were run. Whereas we trained different groups of animals on the odor and spatial span tasks, Beason-Held et al. (1999) trained the same animals on a delayed nonmatching to sample (DNMS) test for objects, and then subsequently on spatial, color, and object span tasks. Thus, the deficits observed across span tasks may reflect an inability of hippocampectomized animals to switch from the use of objects in the initial DNMS to the use of locations in the subsequent spatial span task. Because the color and object span tasks were likewise tested subsequent to the spatial span task, the lesioned animals may have also perseverated in a spatial strategy, even though it was not relevant for the color and object tasks.

\section{Impaired spatial span, DNMS, and alternation performance with hippocampal lesions}

There are at least three possible interpretations of the results obtained on the spatial tasks relative to the odor tasks. First, these results may be viewed as a confirmation of the hypothesis that the hippocampus, in rats, is preferentially involved in the processing of spatial information and spatial working memory (O'Keefe and Nadel, 1978; Jarrard, 1993). Second, it may be argued that hippocampectomized rats were impaired on the cup location tasks because cup location, unlike odor, is defined by its relations to other stimuli. Third, more prosaically, the spatial span task may have simply been more difficult than the odor span task.

Evidence in support of the first view comes from the large number of experiments in rats showing deficits in spatial tasks after hippocampectomy (for review, see Jarrard, 1993). Although our results are consistent with these findings, hippocampectomized rats were able to perform the spatial span task when required to remember one location, but not more. These findings are strikingly consistent with the results of Angeli et al. (1993), in which monkeys with hippocampus lesions (which included damage to the subicular cortex and parahippocampal cortex) could remember one location, but not two. In hippocampectomized rats, Hampson et al. (1999) also observed that the ability to perform a spatial (possibly egocentric) DNMS/DMS tasks was intact at short delays, but impaired at longer delays. Together, these and other recent findings (Whishaw and Jarrard, 1996; Day et al., 1999) suggest that hippocampectomized animals retain some capacity to use spatial information, although their ability to learn new or multiple locations or to retain spatial information across delays is impaired. Thus, structures outside the hippocampus can also support spatial abilities, and this is consistent with the observation that hippocampus lesions that include portions of the ventral subiculum and medial entorhinal cortex yield greater deficits (Morris et al., 1990; Zola-Morgan et al., 1994; Hampson et al., 1999).

A second possibility is that the hippocampus is required for relational memory processing (Cohen and Eichenbaum, 1993), and the spatial span task placed strong demands this ability, whereas the odor span task did not. According to this view, remembering the location of a cup involves processing in memory the relationships among several cues in the environment, and thus may rely on the hippocampus. In contrast, remembering each of several recently experienced odors does not require processing the relationships among those cues or other stimuli, and can thus be accomplished by extrahippocampal structures (Otto and Eichenbaum, 1992). This view is supported by the observation that hippocampectomized rats exhibit impairments in nonspatial, relational tasks (Bunsey and Eichenbaum, 1996).

Finally, it may be argued that the rats with hippocampal lesions were impaired on the spatial span and not the odor span simply because the former was a more difficult task. Comparison of the 
control group's performance in each experiment revealed spatial span was more difficult at spans $>3$. Thus, this possibility cannot be discounted. However, if one compares the performance of the hippocampal groups at a span length in which the control groups' performance was almost identical between the tasks (odor span = $8,93.9 \%$ correct vs spatial span $=1,93.8 \%$ ), the hippocampal group performed as well as the control group on the odor span task $(94.6 \%)$, but significantly worse on the spatial span task (73.4\%). Thus, at a point where the tasks were matched for difficulty by an objective measure of normal performance, hippocampectomized animals were disproportionately impaired on the spatial span task. This result is consistent with the notion that the hippocampus is preferentially involved in memory for spatial or relational information.

\section{The nature of spatial memory dependent on the hippocampus}

On the platform spatial alternation task we observed a significant difference in the accuracy of performance when different dependent measures were considered. When performance was measured by the first cup approached, rats with hippocampal lesions performed at or near chance levels, as on the T-maze. However, when performance was measured by the first cup in which the animal dug, the hippocampectomized rats were impaired relative to controls, but their performance was substantially and significantly above chance levels.

This difference between the approach and dig measures raises the possibility of two separable components of the spatial task: the ability to use spatial information to guide one's behavior to a goal location and the ability to recognize a goal location on arrival. Such a dissociation has been previously suggested in studies of hippocampal disruption and performance of the Morris water maze (Morris et al., 1990; Whishaw et al., 1995; Whishaw and Jarrard, 1996; Day et al., 1999).

\section{Conclusions}

The current results are consistent with previous demonstrations of normal object and odor recognition memory after hippocampal lesions, with signs of an impairment only at a long memory delay. Moreover, the present findings show impressive intact memory for long lists of nonspatial items in rodents, similar to some of the recent findings on monkeys. By contrast, the results from the spatial span, spatial nonmatching to sample, and spatial alternation tasks confirm that the hippocampus and subiculum are necessary for performance on spatial working memory tasks. Because the 12-odor and 12-location span tasks required memory for the same number of cues, the differences observed with hippocampal lesions cannot be attributed to differences in the memory loads between the tasks. However, differences in the "complexity" of the cues, and in particular the demand for processing spatial relations among the cues and the environment, cannot be precluded as a potentially important factor. The observation that rats with hippocampal damage were able to recognize previously visited locations, although they were not able to inhibit their approach to them, suggests that the impairments associated with these lesions may have separable components. Assessment of hippocampectomized animals in tasks that require memory for lists of nonspatial, relationally defined items and tasks that separate navigation from place recognition will clarify the nature of the impairments observed in the current study.

\section{REFERENCES}

Aggleton JP, Brown MW (1999) Episodic memory, amnesia, and the hippocampal-anterior thalamic axis. Behav Brain Sci 22:425-489.

Aggleton JP, Hunt PR, Rawlins JNP (1986) The effects of hippocampal lesions upon spatial and non-spatial tests of working memory. Behav Brain Res 19:133-146.

Aggleton JP, Keen S, Warburton EC, Bussey TJ (1997) Extensive cytotoxic lesions involving both the rhinal cortices and area TE impair recognition but spare spatial alternation in the rat. Brain Res Bull 43:279-287.

Alvarez P, Zola-Morgan S, Squire LR (1995) Damage limited to the hippocampal region produces long-lasting memory impairment in monkeys. J Neurosci 15:3796-3807.

Angeli SJ, Murray EA, Mishkin M (1993) Hippocampectomized monkeys can remember one place but not two. Neuropsychologia 31:1021-1030.

Beason-Held LL, Rosene DL, Killiany RJ, Moss MB (1999) Hippocampal formation lesions produce memory impairment in the rhesus monkey. Hippocampus 9:562-574.

Bunsey M, Eichenbaum H (1996) Conservation of hippocampal memory function in rats and humans. Nature 379:255-257.

Clark RE, Zola SM, Squire LR (1999) Delay-dependent impairments in recognition memory in rats with ibotenic acid lesions restricted to the hippocampus. Soc Neurosci Abstr 25:88.

Cohen NJ, Eichenbaum H (1993) Memory, amnesia, and the hippocampal system. Cambridge, MA: MIT.

Corkin S (1984) Lasting consequences of bilateral medial temporal lobectomy: clinical course and experimental findings in H.M. Semin Neurol 4:249-259.

Day LB, Weisand M, Sutherland RJ, Schallert T (1999) The hippocampus is not necessary for a place response but may be necessary for pliancy. Behav Neurosci 113:914-924.

Dudchenko P, Wood ER, Faherty J, Eichenbaum H (1998) Eight, plus or minus two: olfactory span in the rat, and the contribution of the hippocampus to olfactory working memory. Soc Neurosci Abstr 24:928.

Dusek JA, Eichenbaum H (1998) The hippocampus and transverse patterning guided by olfactory cues. Behav Neurosci 112:762-771.

Eichenbaum H, Fagan A, Mathews P, Cohen NJ (1988) Hippocampal system dysfunction and odor discrimination learning in rats: impairment or facilitation depending on representational demands. Behav Neurosci 102:331-339.

Eichenbaum H, Otto T, Cohen NJ (1994) Two functional components of the hippocampal memory system. Behav Brain Sci 17:449-518.

Ennaceur A, Neave N, Aggleton JP (1996) Neurotoxic lesions of the perirhinal cortex do not mimic the behavioural effects of fornix transection in the rat. Behav Brain Res 80:9-25.

Hampson RE, Jarrard LE, Deadwyler SA (1999) Effects of ibotenate hippocampal and extrahippocampal destruction on delayed-match and nonmatch-to-sample behavior in rats. J Neurosci 19:1492-1507.

Jarrard LE (1989) On the use of ibotenic acid to lesion selectively different components of the hippocampal formation. J Neurosci Methods 29:251-259.

Jarrard LE (1993) On the role of the hippocampus in learning and memory in the rat. Behav Neural Biol 60:9-26.

Kesner RP, Bolland BL, Dakis M (1993) Memory for spatial locations, motor responses, and objects: triple dissociation among the hippocampus, caudate nucleus, and extrastriate visual cortex. Exp Brain Res 93:462-470.

Maguire EA, Burgess N, O'Keefe J (1999) Human spatial navigation: cognitive maps, sexual dimorphism, and neural substrates. Curr Opin Neurobiol 9:171-177.

Meunier M, Bachevalier J, Mishkin M, Murray EA (1993) Effects on visual recognition of combined and separate ablations of the entorhinal and perirhinal cortex in rhesus monkeys. J Neurosci 13:5418-5432.

Miller GA (1956) The magical number seven, plus or minus two: some limits on our capacity for processing information. Psychol Rev 63:81-97.

Morris RGM, Schenk F, Tweedie F, Jarrard LE (1990) Ibotenate lesions of hippocampus and subiculum: dissociating components of allocentric spatial learning. Eur J Neurosci 2:1016-1028.

Mumby DG, Pinel JPJ (1994) Rhinal cortex lesions and object recognition in rats. Behav Neurosci 108:1-8.

Mumby DG, Wood ER, Pinel JPJ (1992) Object-recognition memory is only mildly impaired in rats with lesions of the hippocampus and amygdala. Psychobiology 23:26-36. 
Murray EA (1996) What have ablation studies told us about the neural substrates of stimulus memory? Semin Neurosci 8:13-22.

Murray EA, Mishkin M (1998) Object recognition and location memory in monkeys with excitotoxic lesions of the amygdala and hippocampus. J Neurosci 18:6568-6582.

Neave N, Lloyd S, Sahgal A, Aggleton JP (1994) Lack of effect of lesions in the anterior cingulate cortex and retrosplenial cortex on certain tests of spatial memory in the rat. Behav Brain Res 65:89-101.

O'Keefe J, Nadel L (1978) The hippocampus as a cognitive map. Oxford: Oxford UP.

Olton DS, Feustle WA (1981) Hippocampal function required for nonspatial working memory. Exp Brain Res 41:380-389.

Otto T, Eichenbaum H (1992) Complementary roles of the orbital prefrontal and the perirhinal-entorhinal cortices in an odor-guided delayed-nonmatching-to-sample task. Behav Neurosci 106:762-775.

Rawlins JNP, Lyford GL, Seferiades A, Deacon RMJ, Cassaday HJ (1993) Critical determinants of nonspatial working memory deficits in rats with conventional lesions of the hippocampus or fornix. Behav Neurosci 107:420-433.

Rothblat LA, Kromer LF (1991) Object recognition memory in the rat: the role of the hippocampus. Behav Brain Res 42:25-32.

Scoville WB, Milner B (1957) Loss of recent memory after bilateral hippocampal lesions. J Neurol Neurosurg Psychiatry 20:11-21.

Shaw C, Aggleton JP (1993) The effects of fornix and medial prefrontal lesions on delayed non-matching-to-sample by rats. Behav Brain Res 54:91-102.

Standing L (1973) Learning 10,000 pictures. Q J Exp Psych 25:207-222.
Steele K, Rawlins JNP (1989) Rats remember long lists of nonspatial items. Psychobiology 17:450-452.

Steele K, Rawlins JNP (1993) The effects of hippocampectomy on performance by rats of a running recognition task using long lists of non-spatial items. Behav Brain Res 54:1-10.

Suzuki WA, Zola-Morgan S, Squire LR, Amaral DG (1993) Lesions of the perirhinal and parahippocampal cortices in the monkey produce long lasting memory impairment in the visual and tactile modalities. J Neurosci 13:2430-2451.

Swanson LW (1992) Brain maps: structure of the rat brain. Amsterdam: Elsevier Science BV.

Whishaw IQ, Jarrard LE (1996) Evidence for extrahippocampal involvement in place learning and hippocampal involvement in path integration. Hippocampus 6:513-524.

Whishaw IQ, Cassel J-C, Jarrard LE (1995) Rats with fimbria-fornix lesions display a place response in a swimming pool: a dissociation between getting there and knowing where. J Neurosci 15:5779-5788.

Zola SM, Squire LR, Teng E, Stefanacci L, Buffalo EA, Clark RE (2000) Impaired recognition memory in monkeys after damage limited to the hippocampal region. J Neurosci 20:451-463.

Zola-Morgan S, Squire LR, Amaral DG, Suzuki W (1989) Lesions of perirhinal and parahippocampal cortex that spare the amygdala and hippocampal formation produce severe memory impairment. J Neurosci 9:4355-4370.

Zola-Morgan S, Squire LR, Ramus SJ (1994) Severity of memory impairment in monkeys as a function of locus and extent of damage within the medial temporal lobe memory system. Hippocampus 4:483-495. 